\title{
Switch Device
}

National Cancer Institute

\section{Source}

National Cancer Institute. Switch Device. NCI Thesaurus. Code C50199.

A mechanical or electronic device designed to break or change the connections in a

circuit. 